\title{
Global health education in medical schools (GHEMS): a national, collaborative study of medical curricula
}

\author{
InciSioN UK Collaborative ${ }^{1,2}$
}

\begin{abstract}
Background: Global health is the study, research, and practice of medicine focused on improving health and achieving health equity for all persons worldwide. International and national bodies stipulate that global health be integrated into medical school curricula. However, there is a global paucity of data evaluating the state of global health teaching in medical schools. This study aimed to evaluate the extent of global health teaching activities at United Kingdom (UK) medical schools.
\end{abstract}

Methods: A national, cross-sectional study assessing all timetabled teachings sessions within UK medical courses for global health content during the academic year 2018/19. Global health content was evaluated against a comprehensive list of global health learning outcomes for medical students.

Results: Data from 39 medical courses representing 86\% (30/36) of eligible medical schools was collected. Typically, medical courses reported timetabled teaching covering over three-quarters of all global health learning outcomes. However, a wide degree of variation existed among granular global health learning objectives covered within the different medical courses. On average, each learning outcome had a 79\% [95\% Cl: 73, 83\%] probability of being included in course curricula. There were a number of learning outcomes that had a lower probability, such as 'access to surgeons with the necessary skills and equipment in different countries' (36\%) [95\% Cl: 21, 53\%], 'future impact of climate change on health and healthcare systems' (67\%) [95\% Cl: 50, 81\%], and 'role of the WHO' (54\%) [95\% Cl: 28, 60\%].

Conclusions: This study served as the first national assessment of global health education and curricula within UK medical schools. Through a formalised assessment of teaching events produced by medical schools around the country, we were able to capture a national picture of global health education, including the strengths of global health prioritisation in the UK, as well as areas for improvement. Overall, it appears broad-level global health themes are widely discussed; however, the granularities of key, emerging areas of concern are omitted by curricula. In particular, gaps persist relating to international healthcare systems, multilateral global health agencies such as the WHO, global surgery, climate change and more.

Keywords: Global health, Medical education, Medical school, Collaborative, Curricula, Diversity, Pandemic, WHO

\section{Background}

Global health is the study, research, and practice of medicine focused on improving health and achieving

Correspondence: Soham.bandyopadhyay@yahoo.co.uk; hannahthomas@live.ca

${ }^{1}$ Medical Sciences Division, University of Oxford, Oxford, UK

${ }^{2}$ University of Edinburgh College of Medicine, Edinburgh, UK health equity for all persons worldwide [1]. In modernday society, where health challenges transcend national borders and governments, it is imperative that healthcare professionals (HCPs) understand and engage with global issues to improve healthcare delivery and medical practice around the world. For instance, diseases are able to cross geographical boundaries more rapidly than ever

(c) The Author(s). 2020 Open Access This article is licensed under a Creative Commons Attribution 4.0 International License, which permits use, sharing, adaptation, distribution and reproduction in any medium or format, as long as you give appropriate credit to the original author(s) and the source, provide a link to the Creative Commons licence, and indicate if changes were made. The images or other third party material in this article are included in the article's Creative Commons licence, unless indicated otherwise in a credit line to the material. If material is not included in the article's Creative Commons licence and your intended use is not permitted by statutory regulation or exceeds the permitted use, you will need to obtain permission directly from the copyright holder. To view a copy of this licence, visit http://creativecommons.org/licenses/by/4.0/ The Creative Commons Public Domain Dedication waiver (http://creativecommons.org/publicdomain/zero/1.0/) applies to the data made available in this article, unless otherwise stated in a credit line to the data. 
before [2] and have become an ever increasing threat to global security [3]. HCPs are key workers for mitigating and managing disease threats to maximise human safety and survival. In order to prevent and prepare for future pandemics, it is key that all HCPs are given the training to understand international disease epidemiology and trends. Equally, a better understanding of whole population health and an appreciation of the complex relationships between certain communities, ill health and health inequities is essential for effective healthcare leadership in service planning [4]. Moreover, it is the ethical responsibility of HCPs, as health advocates, to learn from one another transnationally to improve health around the world [5]. The aforementioned concepts are core principles of medical practice [6,7]. Therefore, these professional values must be fostered and encouraged at an early stage of medical training [8].

There have been repeated calls for more robust global health education within medical training programmes from students [9-11] and faculty alike [5, 12-14]. International legislative voices, such as the World Health Organisation (WHO) now insist that global health be included in medical school curricula [15-17]. Many medical schools incorporate global health education into their curriculum through student selected (optional) modules or through intercalated Bachelor of Science degrees $[6,14]$. However, global health principles have been mandated to be included in medical school curricula as essential, non-elective modules [12, 18-21]. Documents from a regulatory body for medical professionals in the United Kingdom (UK) detail specific global health learning outcomes and competencies that medical students are expected to achieve by graduation [18-20].

However, it is unclear whether medical schools have integrated global health learning outcomes into their compulsory syllabi. This is because there is a paucity of data evaluating the current state of global health teaching in medical schools. In particular, there is limited data on curricula, teaching methods and quantity of global health education outside of the United States (US) [22]. The Global Health Education in Medical Schools (GHEMS) study is a UK based, multicentre, collaborative study that aimed to characterise global health education and curricula within UK medical schools. The primary aim of this study is to formally map the extent of timetabled global health teaching activities within UK medical schools. This information can be used by medical schools and regulators to ensure that an adequate global health education is being provided to all medical students.

\section{Method}

\section{Study design and participants}

The study was conducted as per the previously published study protocol [23]. This was a national study evaluating global health education within UK medical school curricula during the academic year 2018/19. Medical schools were eligible to participate if they were recognised by the General Medical Council (GMC) as being able or being under review to award a UK medical degree in 2019. Data variables were based on a list of global health learning outcomes published by the Global Health Learning Outcomes Working Group (GHLOWG) [12]. This list was developed through consultations with a consortium of global health stakeholders, comprising universities, the public, the Royal Colleges, and other professional, educational, and civil society bodies, with discussions focused on the targeted outcomes listed in guidelines published by the GMC. For the purposes of this study, the list was amended following consultations with the lead author of the GHLOWG publication [12] and a board of cross-specialty advisors comprised of educationalists and global health professionals. The list was modified to improve interpretability for students and to add a learning objective (LO) related to global surgery - recently added as a mandatory LO to the national undergraduate curriculum in surgery [24] - to produce the final list of 42 LOs (Appendix 1).

Two collaborators were recruited at each participating centre by utilising existing networks of national and local bodies interested in global health. All collaborators attended a training and support session delivered by the GHEMS steering committee. Following the training session, collaborators ensured the correct departmental approval had been achieved prior to collecting data. The GHEMS steering committee maintained regular contact with all data collectors in order for collaborators to receive prompt clarifications regarding project uncertainties and provide feedback on local issues or questions raised by their institution. The authorship of this paper was modelled according to previous collaborative publications [25].

\section{Data collection}

Collaborators obtained timetables for all curricular years of medicine at their institution for the academic year 2018/19. Separate timetables were obtained for undergraduate and graduate-entry medicine course curricula as timetabled teaching often differs between courses within the same university due to differences in courselength: undergraduate courses are typically five to six years in length, while graduate-entry courses are usually four to five years in length. Each collaborator identified global health curricular events from the timetables and independently coded them to populate a standardised data collection template formulated by the steering committee as per the study protocol (Appendix 2) [23]. Collaborators were advised not to discuss institution results with each other during the data collection phase. Following data collection, the data points in agreement $(90 \%$ of all data points) between collaborators at the same institution were recorded. For the $10 \%$ of data points encountering 
disagreement, conflicts were resolved by mutual agreement or through a member of the GHEMS steering committee reviewing the evidence and making the final judgement. All final decisions were relayed back to the collaborators and feedback was sought from medical leadership to ensure that coding accurately represented the state of global health teaching within their medical school. Following this, permission was obtained from selected participating centres to utilise the global health content taught at their institution to create an amalgamation of frequently discussed topics (Appendix 3).

\section{Study variables}

Variables pertaining to characteristics of the timetabled learning event - course year, undergraduate/graduate-entry course, and style of teaching - were collected. The assigned LOs for each timetabled event were recorded. The duration of time that each timetabled event spent on a global health LO was not recorded. Timetabled events for student selected modules and intercalated years were excluded from further analysis. Variables pertaining to medical elective placements at each institution were also collected, including length of the elective and the year of study. The content and location of electives are likely to be highly variable from one student to another, and as such it was beyond the scope of this study to collect more granular data about electives.

\section{Statistical analysis}

Data was analysed using descriptive statistics to determine the proportion of LOs included in each UK medical course curriculum. For individual LOs, we calculated the proportion of medical schools reported to be delivering that LO. For groups of LOs (themes and sub-themes), we determined the median number, mean proportion, and range of LOs covered within that group across reporting schools. We used exact binomial methods to estimate $95 \%$ confidence intervals around proportions. We applied a multilevel Poisson model with robust variance to compare coverage of individual and grouped LOs to average coverage using dummy variables, modelling variance between medical schools as a random effect. We also used this approach to assess differences between LO coverage between undergraduate and graduateentry medical courses. Where reported, confidence intervals were $95 \%$ and $p$-values were two-tailed. LOs and sub-themes that were covered by fewer than $80 \%$ of participating centres have been highlighted, and divided into those that are covered by some medical courses $(60-80 \%)$, and those that are covered by few medical courses $(<60 \%)$.

\section{Ethical considerations}

Advice on ethical approval was sought from King's College London Research Ethics Committee and Oxford Medical Sciences Inter-Divisional Research Ethics Committee. Both committees stated this study did not require ethical approval.

\section{Role of the funder}

The author(s) received no financial support for the research, authorship and/or publication of this article.

\section{Results}

Characteristics of timetabled teaching sessions

Eighty-three percent of eligible UK medical schools were represented in this study (30/36). Eligible centres were excluded due to an inability to recruit collaborators or a lack of permission granted by the prospective institution. Among consenting institutions, 23 were located in England, five in Scotland, two in Wales and none in Northern Ireland. Data was extrapolated based on the type of medical course offered within the institution: undergraduate and/or graduate-entry course. Overall, data from 39 medical courses was collected: 28 undergraduate medical courses and 11 graduate-entry medicine courses. A range of teaching styles were employed by each medical course to deliver LO content. Undergraduate and graduate-entry courses had a similar distribution of pedagogical techniques (Fig. 1). The majority of teaching $(74 \%)$ was delivered via lectures in both undergraduate $(72 \%)$ and graduate-entry $(83 \%)$ courses. The remainder of the teaching was provided via small group teaching (13\%; undergraduate:14\%; graduate-entry: $10 \%)$, problem-based learning (8\%; undergraduate: $9 \%$; graduate-entry: $0.1 \%)$, case-based learning ( $2 \%$; undergraduate:1\%; graduate-entry:6\%), and self-directed learning (4\%; undergraduate:4\%; graduate-entry: $1 \%)$.

\section{Coverage of Global Health LOs by UK medical courses}

A total of 38 (38/39, 97\%), 17 (17/39, 44\%), and four (4/39, $10 \%)$ medical courses reported that they taught all global health themes, sub-themes, and LOs, respectively. Overall, medical courses taught the majority $(15 / 17,88 \%)$ [95\% CI: 87, 95\%] of global health sub-themes. The mean number of global health objectives incorporated into all timetabled teaching of any one medical course was 33/42 (79\%) [95\% CI: 73, 83\%]. This mean was skewed left due 2 medical courses covering fewer than 20 LOs, as shown in Fig. 2. There was considerable variation with regards to the number of learning objectives covered by medical courses within each theme and sub-theme (Table 1). The greatest disparity of mean LO coverage was between the themes of global burden of disease (89\%) [95\% CI: 86, 92\%] and organisation of health services (64\%) [95\% CI: 60, 68\%].

\section{Theme one: global burden of disease}

All medical courses $(n=39)$ included timetabled content pertaining to the 'global burden of disease' theme. Nested within this theme, the following three sub-themes: 'the health of populations', 'migration and disease' and 'pandemics' were offered within the teaching of $100 \%$ (39/39), $100 \%(39 / 39)$, and $90 \%(35 / 39)$ of medical courses, 


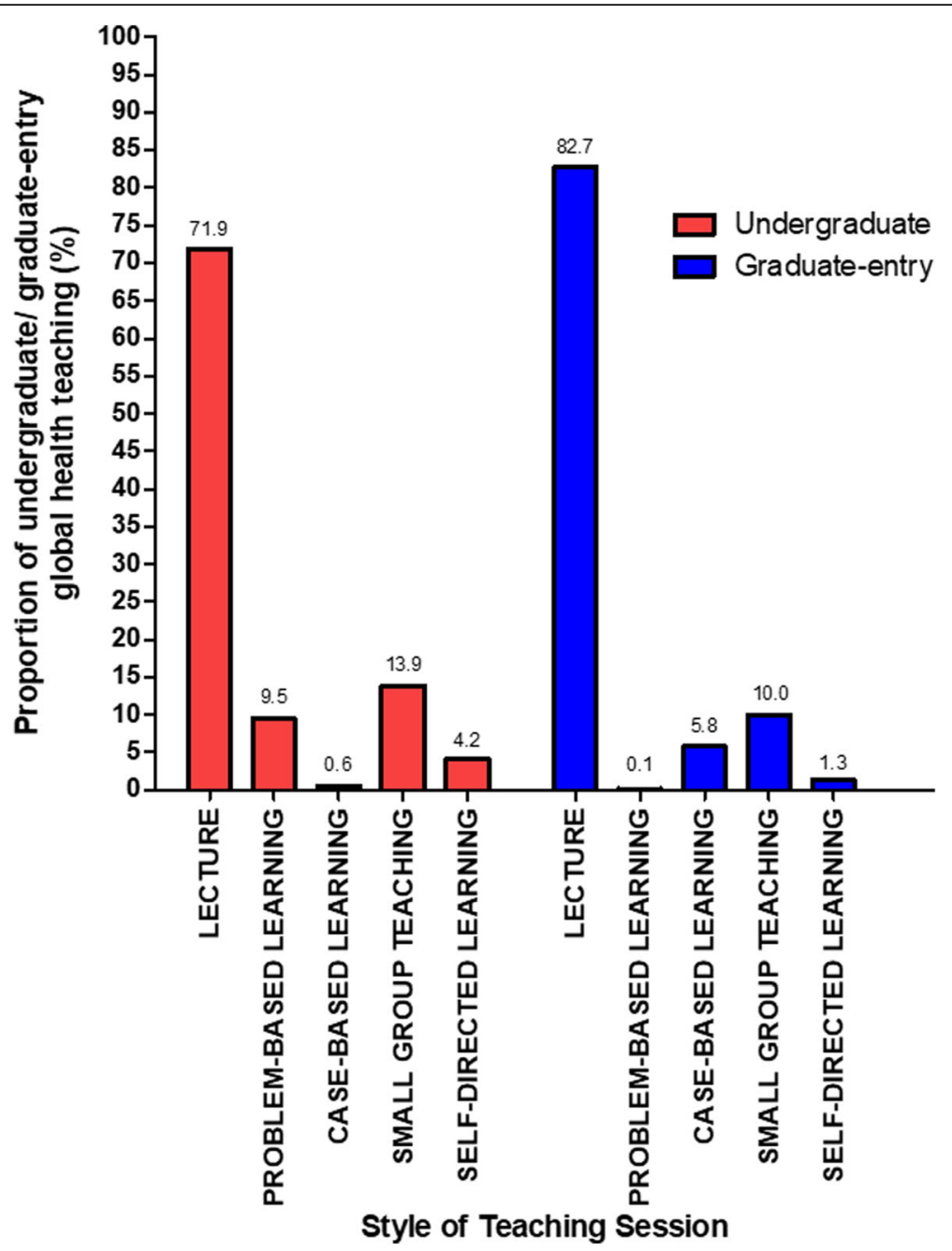

Fig. 1 Teaching styles employed by medical courses to deliver content of global health learning objectives

respectively. The three sub-themes were further subdivided into 11 global health LOS that were included in 89\% (35/ 39) [95\% CI: 74, 96\%] of medical courses. Moreover, all medical courses documented the inclusion of 'principles of disease prevention and control in a global setting' and 'diseases commonly seen in certain communities' into timetabled teaching (Fig. 3 and Table 2). In addition, 'mortality and morbidity statistics between countries' and 'nutrition on health' was covered by all undergraduate medical courses and all graduate-entry medical courses, respectively. There was a significant difference between the proportion of undergraduate medical courses that reported they had scheduled teaching on 'global, national, and local efforts to control pandemics' (27/ $28,96 \%$ ) and the proportion of graduate-entry medical courses that reported they had timetabled teaching on this $\operatorname{LO}(8 / 11,73 \%)(p=0.0326)$.
Theme two: socio-economic, cultural, and environmental conditions

All medical courses documented inclusion of the theme 'socio-economic, cultural, and environmental conditions' as part of timetabled teaching. The six sub-themes that formed this broader theme: 'effects of violence and war on health', 'health inequity' and 'socioeconomic factors affecting health', 'political factors affecting health', 'environmental and occupational hazards and ways to mitigate their effects' and 'future impact of climate change on health and healthcare systems' were included in timetabled learning opportunities of 62\% (24/39), 100\% (39/ 39), $100 \%$ (39/39), 90\% (35/39), 85\% (33/39), and 67\% (26/39) of courses, respectively (Fig. 3 and Table 2). On average, all six global health LOs within this theme were reported to be included in the timetabled teaching of $85 \%$ (33/39) [95\% CI: 67, 100\%] of medical courses. 


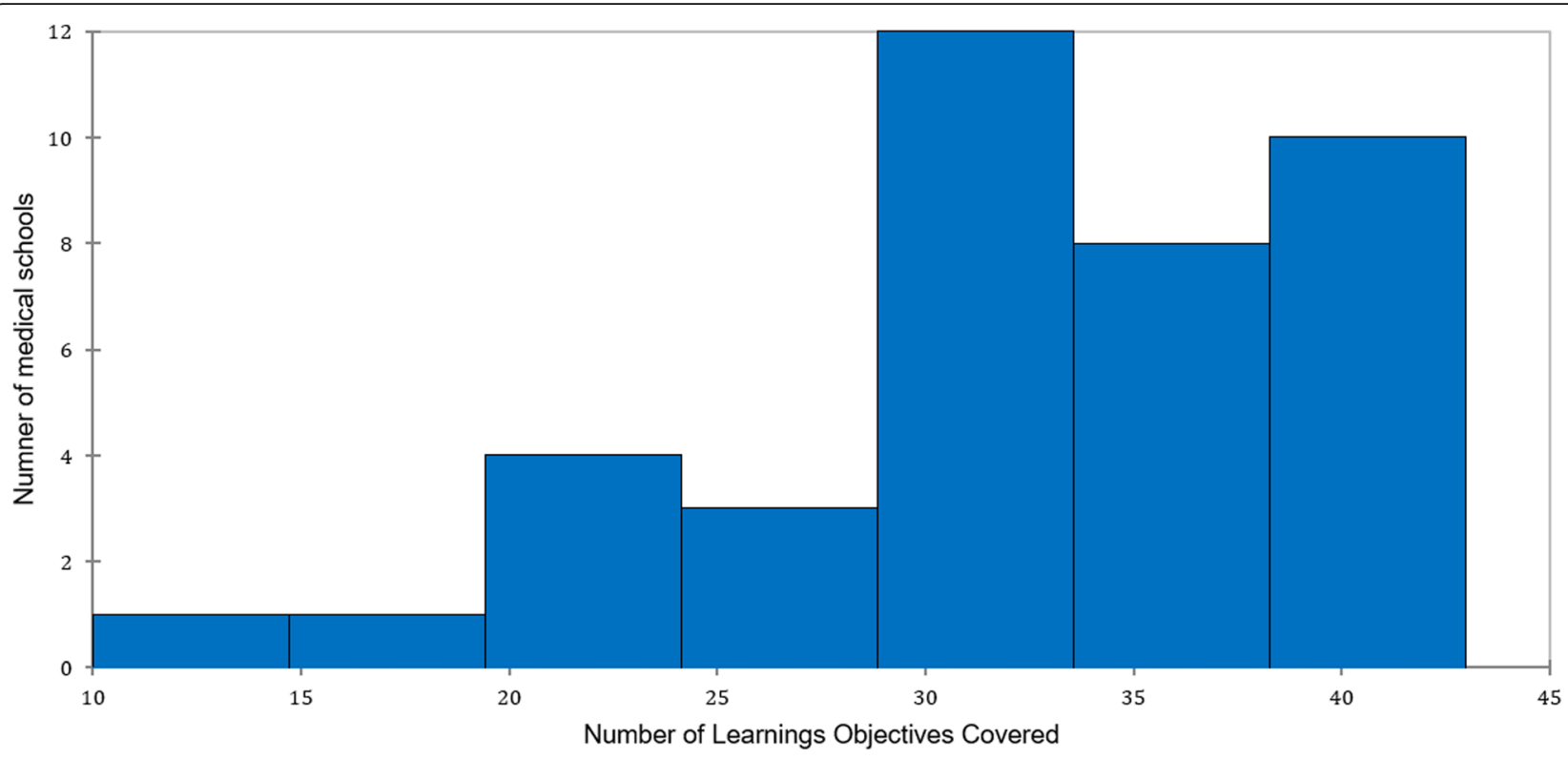

Fig. 2 Histogram of the number of learning objectives (max 42) covered by medical schools in the UK

\section{Theme three: organisation of health services}

All medical courses included timetabled content pertaining to the 'organisation of health services' theme within their curricula. The three sub-themes embedded within this broader theme: 'health systems', 'workforce' and 'global governance,' were reported to be incorporated into scheduled teaching of 100\% (39/39), 95\% (37/39), and $85 \% 33 / 39$ ) of medical courses, respectively. On average, each of the 13 global health LOs nested under this theme were included in the timetabled learning opportunities of $64 \%$ (25/39) [95\% CI: 55, 77\%] of medical courses. This mean was skewed right by the fact that all medical courses documented the inclusion of content pertaining to the 'structure and function of the NHS' into teaching (Fig. 3 and Table 2). Three LOs were not included in any teaching sessions by the majority (> $50 \%$ ) of medical courses: access to surgeons with the necessary skills and equipment in different countries (14/ $39,36 \%)(p=0.003)$, diversity in the workforce $(16 / 39$, $41 \%)(p=0.009)$, and private sector involvement in UK healthcare $(17 / 39,44 \%)(p=0.015)$.

\section{Theme four: human rights and ethics}

Ninety-seven percent of medical courses (38/39) reported that they covered the theme of 'human rights and ethics' as part of timetabled teaching. Embedded within this theme, the following three sub-themes: 'law and ethics', 'human rights' and 'vulnerable groups' were included within the learning opportunities of 97\% (38/39), $92 \%(36 / 39)$, and $90 \%(35 / 39)$ of medical courses, respectively. On average, each of the seven global health LOs that form the theme of 'human rights and ethics,' was reported to be included in the scheduled teaching of 77\% (30/39) [95\% CI: 65, 88\%] of medical courses (Fig. 3 and Table 2). This mean was skewed left by the relatively few medical courses that had timetabled teaching about the impact of international law on UK medical practice' $(23 / 39,59 \%)$. Of note, all graduate-entry medical courses included 'ethics of healthcare delivery' into timetabled teaching.

\section{Theme five: cultural diversity and health}

Ninety-seven percent of medical courses (38/39) documented inclusion of the theme 'global burden of disease' within timetabled teaching. The two sub-themes that formed this broader theme: 'communication' and 'health determinants' were reported to be incorporated into the timetabled teaching of 97\% (38/39), and $92 \%(36 / 39)$ of all medical courses, respectively. On average, each of the five global health LOs embedded within the umbrella theme, was reported to be included within scheduled learning opportunities of $87 \%$ (34/39) [95\% CI: 73, 100\%] of medical courses (Fig. 3 and Table 2). This mean was skewed left by the relatively few medical schools that had timetabled teaching about 'how to communicate with someone who does not speak English' (26/39, 67\%). Of note, all graduate-entry medical courses reported inclusion of 'being informed of cultural differences from people from that culture', 'sociology and psychology of the varied responses of groups and societies to disease', and 'health behaviours and outcomes of specific backgrounds' into their timetabled teaching. 
Table 1 Learning objectives taught by medical courses divided by theme and sub-theme

\begin{tabular}{|c|c|c|c|c|c|c|c|}
\hline \multicolumn{4}{|l|}{ Theme } & \multicolumn{4}{|l|}{ Sub-Theme } \\
\hline & $\begin{array}{l}\text { Number } \\
\text { of LOs }\end{array}$ & $\begin{array}{l}\text { Median number } \\
\text { of LOs covered } \\
\text { by medical } \\
\text { courses (range) }\end{array}$ & $\begin{array}{l}\text { Mean \% of LOs } \\
\text { covered by } \\
\text { medical courses } \\
(95 \% \mathrm{Cl})\end{array}$ & & $\begin{array}{l}\text { Number } \\
\text { of LOs }\end{array}$ & $\begin{array}{l}\text { Median number } \\
\text { of LOs covered by } \\
\text { medical courses } \\
\text { (range) }\end{array}$ & $\begin{array}{l}\text { Mean } \% \text { of LOs } \\
\text { covered by } \\
\text { medical courses } \\
(95 \% \mathrm{Cl})\end{array}$ \\
\hline \multirow[t]{3}{*}{$\begin{array}{l}\text { Global Burden } \\
\text { of Disease }\end{array}$} & 11 & $10(6-11)$ & $89.3(86.0-92.4)$ & $\begin{array}{l}\text { The Health of } \\
\text { Populations }\end{array}$ & 6 & $6(2-6)$ & $91.9(87.6-95.0)$ \\
\hline & & & & $\begin{array}{l}\text { Migration and } \\
\text { Disease }\end{array}$ & 3 & $3(1-3)$ & $87.2(79.7-92.6)$ \\
\hline & & & & Pandemics & 2 & $2(0-2)$ & $84.6(74.7-91.8)$ \\
\hline \multirow{7}{*}{$\begin{array}{l}\text { Socioeconomic, } \\
\text { Cultural, and } \\
\text { Environmental } \\
\text { conditions }\end{array}$} & 6 & $5(2-6)$ & $83.8(78.4-88.2)$ & $\begin{array}{l}\text { Effects of violence } \\
\text { and war on health }\end{array}$ & 1 & $1(0-1)$ & $61.5(44.6-76.6)$ \\
\hline & & & & Health inequity & 1 & $1(1-1)$ & $100(91.0-100)$ \\
\hline & & & & $\begin{array}{l}\text { Socioeconomic } \\
\text { Factors affecting } \\
\text { health }\end{array}$ & 1 & $1(1-1)$ & $100(91.0-100)$ \\
\hline & & & & $\begin{array}{l}\text { Political Factors } \\
\text { affecting health }\end{array}$ & 1 & $1(0-1)$ & $89.7(75.8-97.1)$ \\
\hline & & & & $\begin{array}{l}\text { Environmental and } \\
\text { occupational hazards } \\
\text { and ways to mitigate } \\
\text { their effects }\end{array}$ & 1 & $1(0-1)$ & $84.6(69.4-94.1)$ \\
\hline & & & & $\begin{array}{l}\text { Future impact of } \\
\text { climate change on } \\
\text { health and healthcare } \\
\text { systems }^{\mathrm{a}}\end{array}$ & 1 & $1(0-1)$ & $66.7(49.8-80.9)$ \\
\hline & & & & $\begin{array}{l}\text { Political Factors } \\
\text { affecting health }\end{array}$ & 1 & $1(0-1)$ & 89.7 (75.8-97.1) \\
\hline \multirow{3}{*}{$\begin{array}{l}\text { Organisation of } \\
\text { health services }\end{array}$} & 13 & $8(2-13)$ & $63.9(59.6-68.1)$ & Health Systems ${ }^{a}$ & 5 & $4(1-5)$ & $70.8(63.8-77.0)$ \\
\hline & & & & Workforce $^{a}$ & 4 & $3(0-4)$ & $64.1(56.0-71.6)$ \\
\hline & & & & Global Governance ${ }^{b}$ & 4 & $2(0-4)$ & $55.1(47.0-63-1)$ \\
\hline \multirow{3}{*}{$\begin{array}{l}\text { Human Rights } \\
\text { and Ethics }\end{array}$} & 7 & $6(0-7)$ & $76.9(71.5-81.8)$ & Law and Ethics ${ }^{a}$ & 2 & $2(0-2)$ & $78.2(67.4-86.8)$ \\
\hline & & & & Human Rights & 2 & $2(0-2)$ & $83.3(73.2-90.8)$ \\
\hline & & & & Vulnerable groups ${ }^{a}$ & 3 & $2(0-3)$ & $71.8(62.7-79.7)$ \\
\hline \multirow{2}{*}{$\begin{array}{l}\text { Cultural Diversity } \\
\text { and Health }\end{array}$} & 5 & $5(0-5)$ & $86.7(81.1-91.1)$ & Communication & 3 & $3(0-3)$ & $83.8(75.8-89.9)$ \\
\hline & & & & Health determinants & 2 & $2(0-2)$ & $91.0(82.3-96.3)$ \\
\hline
\end{tabular}

Note: LOs learning objectives. ${ }^{a}$ Sub-themes that are covered by some medical courses $(60-80 \%) .{ }^{b}$ Sub-themes that are covered by few medical courses $(<60 \%)$

\section{Medical electives}

The average length of elective opportunities offered at each UK medical course was 6.8 weeks. The length of the elective opportunities ranged from four weeks to ten weeks. Overall, 13 medical schools $(43 \%, 13 / 30)$ - offering undergraduate and/or graduate entry medical courses - reported compulsory pre-elective timetabled teaching for medical students, with topics ranging from appropriate vaccinations to respecting local cultures. Two medical schools held post-elective face-to-face reflection sessions with students.

\section{Discussion}

This study affirms that the majority of learning outcomes produced by the GHLOWG are being taught as part of timetabled teaching within the majority of UK undergraduate and graduate-entry medical courses. The pedagogical method utilised by the majority of the teaching sessions are lectures. Broad-level themes and subthemes are well-covered within curricula; however, there is considerable variation when it comes to more specific global health LO opportunities. For instance, while all medical courses delivered teachings on the structure and function of the National Health Services (NHS), broader discussions surrounding healthcare systems and the dynamic involvement of the private and charitable sectors were neglected. Similarly, it was estimated that only over half of medical courses provided teachings on the WHO's framework and role, leaving much to speculate regarding students' education of international global health surveillance and security. Further, few medical courses included content on highly topical global health issues, such as global surgery and climate change. 
Proportion of medical schools teaching each learning objective
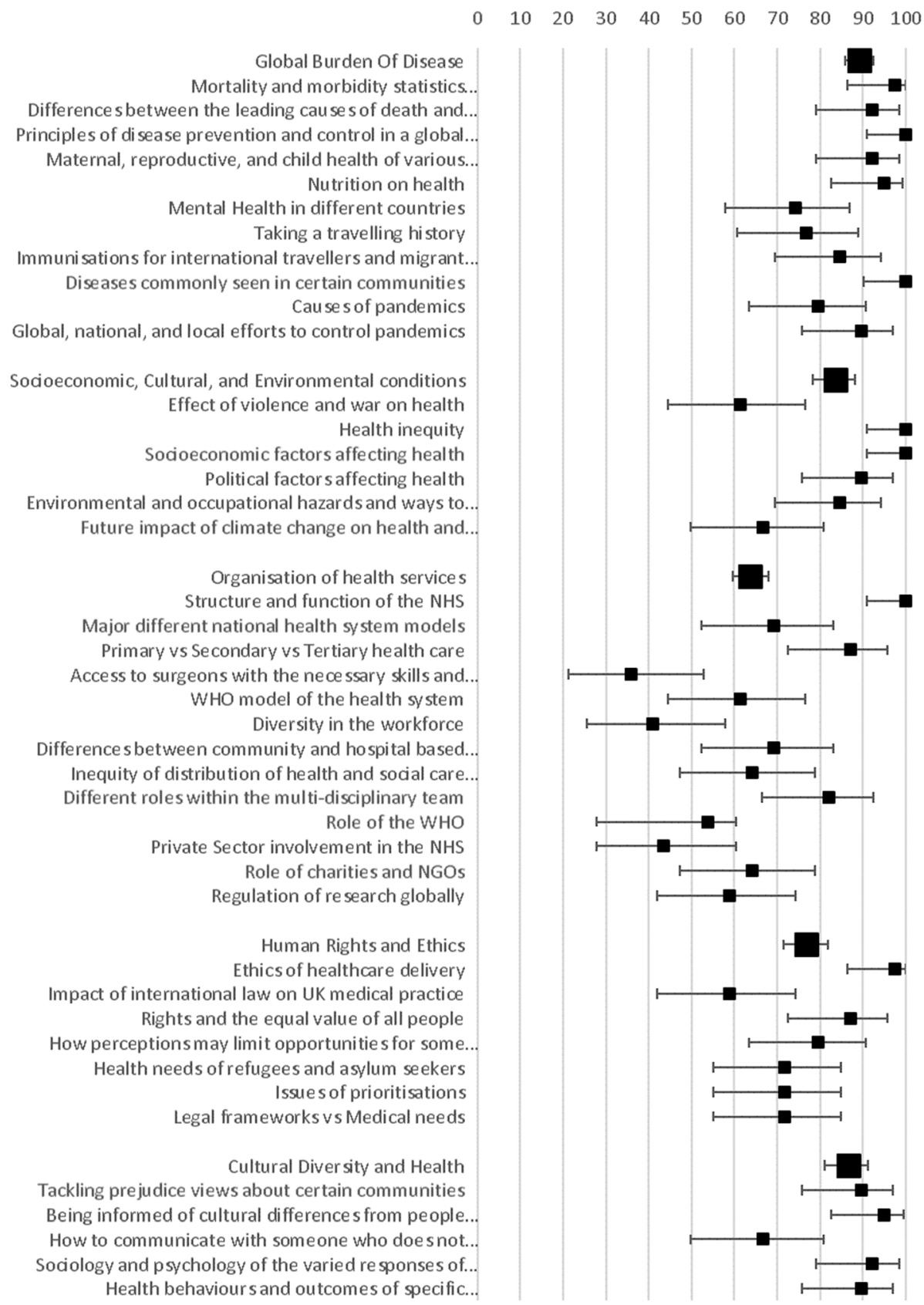

Fig. 3 Proportion of medical schools that covered each learning objective, grouped by learning objective and theme. The average proportion of learning objectives covered by medical courses for each theme is also shown; this is indicated by the larger black boxes. Error bars indicate the $95 \%$ confidence interval

Trends were largely similar between undergraduate and graduate-entry courses; however, graduate-entry courses were less likely to cover content pertaining to pandemics. Finally, although medical schools offered approximately seven weeks of elective time, there were minimal learning opportunities pertaining to elective preparation or debriefing.
By gaining a greater understanding into global health topics exposed to UK medical students, we were able to ascertain the key lessons being instilled in the future NHS workforce. The inconsistent coverage of certain LOs between medical schools, indicates distinct differences in standards of global health education across the UK. Translational topics including awareness of cultural 
Table 2 The proportion of medical schools that have teaching sessions related to each learning objective

\begin{tabular}{|c|c|}
\hline LO & $\begin{array}{l}\% \text { of medical } \\
\text { THEME }\end{array}$ \\
\hline \multicolumn{2}{|l|}{ Global Burden Of Disease } \\
\hline Mortality and morbidity statistics between countries & $97.4(86.5-99.9$ \\
\hline Differences between the leading causes of death and disability in different countries & $92.3(79.1-98.4$ \\
\hline Principles of disease prevention and control in a global setting & $100(91-100)$ \\
\hline Maternal, reproductive, and child health of various countries & $92.3(79.1-98.4$ \\
\hline Nutrition on health & $94.9(82.7-99.3$ \\
\hline Mental Health in different countries ${ }^{\mathrm{a}}$ & $74.4(57.9-87)$ \\
\hline Taking a travelling history ${ }^{\mathrm{a}}$ & $76.9(60.7-88.9$ \\
\hline Immunisations for international travellers and migrant communities & $84.6(69.5-94.1$ \\
\hline Diseases commonly seen in certain communities & $100(90.1-100)$ \\
\hline Causes of pandemics $^{a}$ & $79.5(63.5-90.7$ \\
\hline Global, national, and local efforts to control pandemics & $89.7(75.8-97.1$ \\
\hline
\end{tabular}

\section{Socioeconomic, Cultural, and Environmental conditions}

Effect of violence and war on health ${ }^{a}$

$61.5(44.6-76.6)$

Health inequity

$100(91-100)$

Socioeconomic factors affecting health

$100(91-100)$

Political factors affecting health

$89.7(75.8-97.1)$

Environmental and occupational hazards and ways to mitigate their effects

$84.6(69.4-94.1)$

Future impact of climate change on health and healthcare systemsv

$66.7(49.8-80.9)$

\section{Organisation of health services}

Structure and function of the NHS

$100(91-100)$

Major different national health system models ${ }^{\mathrm{a}}$

$69.2(52.4-83.0)$

Primary vs Secondary vs Tertiary health care

$87.2(72.6-95.7)$

Access to surgeons with the necessary skills and equipment in different countries ${ }^{b}$

$35.9(21.2-52.8)$

WHO model of the health system ${ }^{a}$

$61.5(44.6-76.6)$

Diversity in the workforce ${ }^{b}$

$41(25.6-57.9)$

Differences between community and hospital-based staff ${ }^{b}$

$69.2(52.4-83.0)$

Inequity of distribution of health and social care professionals ${ }^{\mathrm{a}}$

$64.1(47.2-78.8)$

Different roles within the multi-disciplinary team

$82.1(66.5-92.5)$

Role of the $\mathrm{WHO}^{\mathrm{b}}$

$53.9(27.8-60.4)$

Private Sector involvement in the $\mathrm{NHS}^{\mathrm{b}}$

$43.6(27.8-60.4)$

Role of charities and $\mathrm{NGOs}^{\mathrm{a}}$

$64.1(47.2-78.8)$

Regulation of research globally ${ }^{b}$

$59(42.1-74.4)$

\section{Human Rights and Ethics}

Ethics of healthcare delivery

$97.4(86.5-99.9)$

Impact of international law on UK medical practice ${ }^{b}$

$59(42.1-74.4)$

Rights and the equal value of all people

$87.2(72.6-95.7)$

How perceptions may limit opportunities for some people ${ }^{a}$

$79.5(63.5-90.7)$

Health needs of refugees and asylum seekers ${ }^{a}$

$71.8(55.1-85.0)$

Issues of prioritisations ${ }^{a}$

$71.8(55.1-85.0)$

Legal frameworks vs Medical needs ${ }^{\mathrm{a}}$

$71.8(55.1-85.0)$

\section{Cultural Diversity and Health}


Table 2 The proportion of medical schools that have teaching sessions related to each learning objective (Continued)

\begin{tabular}{ll}
\hline LO & $\begin{array}{l}\text { \% of medical courses that taught LO (95\% CI) } \\
\text { THEME }\end{array}$ \\
\hline Being informed of cultural differences from people from that culture & $94.9(82.7-99.4)$ \\
How to communicate with someone who does not speak English ${ }^{a}$ & $66.7(49.8-80.9)$ \\
Sociology and psychology of the varied responses of groups and societies to disease & $92.3(79.1-98.4)$ \\
Health behaviours and outcomes of specific backgrounds & $89.7(75.8-97.1)$ \\
\hline
\end{tabular}

Note: LOs learning objectives. ${ }^{a}$ LOs that are covered by some medical courses $(60-80 \%)$. ${ }^{b}$ LOs that are covered by few medical courses $(<60 \%)$

differences, the ethics of healthcare delivery and diseases commonly seen in certain migratory communities, are universally applicable to all students' future careers as NHS clinicians. However, less frequently discussed topics such as healthcare systems, global health security and surveillance, global surgery and climate change also necessitate attention in order to ensure these needs do not go unmet $[26,27]$. In particular, the emergence of the novel coronavirus pandemic reinforces these essential global health lessons. A thorough understanding of not just the hierarchy of the NHS, but also the structure and functioning of international healthcare systems affords students a greater opportunity to understand global health security and pandemic preparedness [28]. When the Ebola epidemic spread across West Africa, there was an acute need for medical professionals to adopt less traditional roles and new knowledge. A renewed spotlight was placed on the need for comprehensive health systems models, with integrated global health security [29]. Our study noted that few medical courses included teaching about the WHO, marking a major gap in education surrounding global multilateral health agencies. The WHO plays a vital role in preventing and addressing disease around the world, and many argue that the coronavirus pandemic has reinforced the importance of this role [30]. Overall, as future clinicians, medical students are in the unique position to harness the lessons of pandemic response to step into professional roles that mitigate disease threats [31]. Developed by the American Medical Association (AMA), health systems science (HSS) is a novel approach designed to challenge medical curricula to include regular, interdisciplinary, health systems teaching [32]. Trialled by a few medical schools in the US, HSS calls for timetabled emphasis on healthcare policy, health information technology, systems thinking and more [32]. Authors of the HSS movement caution that such reform must be accompanied by addressing student-perceived barriers such as the basic science-focused design of formal medical assessments and additional stressors [33].

In addition to the above global health needs, emerging topics such as global surgery and climate change were covered infrequently by medical curricula. In 2015, the Lancet Commission on Global Surgery released a landmark report detailing the needs of five billion people who lack access to safe, timely and affordable surgical care [34]. Advocates reinforced surgery as an "indivisible, indispensable part of health care," with moral and economic arguments for future investment by nations [34]. At a higher-tier in the UK, the Royal Colleges have affirmed their commitment to addressing inequities in surgical care, through dynamic collaborations with the College of Surgeons of East, Central and Southern Africa (COSECSA) and SURG-Africa, among others [35]. Moreover, global surgery has been ratified by the Royal College of England as an essential topic among surgical undergraduate curriculum [24]. With parallel calls for strengthening global surgery education at the traineelevel, learning opportunities pertaining to surgical inequities are crucial for inclusion in medical school curricula [36]. Similarly, as literature continues to emerge detailing the links between climate change and health, such issues must be discussed among the future health workforce [37]. Global temperature shifts, wildfires, changing tides, disrupted animal habitats and more, challenge the homeostasis of our existing disease patterns, including the presentation of novel infectious diseases. Given the topic relevance, medical students must be equipped with climate change knowledge, in order to serve as advocates and counsel for patient wellbeing [38]. The One Health approach may serve as a blueprint for schools looking to further consider the complex effect of human, animal and environmental health on emerging disease threats [39]. Finally, elective preparation and debriefing is an area of need that has been identified by GHEMS and others [11]. With $90 \%$ of UK medical students participating in a medical elective abroad, it is particularly important to ensure students are equipped with the necessary knowledge, awareness and cultural humility to meaningfully work in settings of varied resourcelevels as well as appropriately learn about other cultures and medical systems [40]. Given medical electives are a valuable opportunity for many students to consolidate and contextualise their global health teaching, it is a significant missed opportunity that only $40 \%$ of medical schools provide a mandatory timetabled preparatory course. 
The GHEMS study comprehensively captured data from $83 \%$ of eligible medical schools in the UK. This has been possible through collaboration amongst students. Such collaborative projects which are driven for students, by students, have been validated internationally and have a proven record of generating robust data [25, 41]. Amongst participating medical schools, approximately $90 \%$ of centres had two collaborators independently coding all timetabled global health learning events, thereby increasing the reliability of the data. The consistency and reproducibility of the data was ensured by providing centralised training to collaborators and publishing an open access comprehensive study protocol [23]. Through the GHEMS study, local results were disseminated to institutional leadership to facilitate ongoing discussions surrounding educational quality improvement. This crucial link in the audit loop, ensures that participating centres can benefit from study results and identify strategies for global health education reform at their respective institution. Moreover, our study is timely, as several new medical schools (including the Universities of Sunderland, Lincoln and Edgehill) are currently developing their curricula. In addition, as the world combats a novel infectious disease pandemic, concerns arise surrounding the under-representation and variance of key LOs within medical school curricula. This warrants further investigation into the reasoning behind curricula development. Similar research has been conducted in both the US and Canada through formalised organisations such as the Global Health Education Consortium [22]. National recommendations have also yielded a diverse range of global health learning opportunities among American medical schools [11], suggesting the need for greater international reform of global health education. The results of GHEMS serve to guide schools in developing comprehensive curricula that addresses all recommended global health LOs. Finally, it is interesting to note that most global health LOs are being taught via lectures: the most base form of information transfer; these LOs are topics that lend themselves to in depth discussions between students. The paucity of small group teaching around global health may be an indicator that there has not been sufficient emphasis on global health to make it more of a "skill" than just knowledge.

The cross-sectional nature of our study restricted the depth of gathered curricular information. A continual audit cycle of global health teaching across multiple years would reveal the true nature of global health curricular progression within medical schools. In addition, data collection was limited to timetabled information found within institutional virtual learning environments and schedules. In this regard, authors were unable to ascertain whether planned teaching matched actual learning opportunities delivered to students. Although data pertaining to the length of each teaching session was collected, we believe this was not representative of the breadth of nuance of coverage afforded to each LO. For example, while a topic may have been listed within the learning points of a lecture, we were unable to ascertain what proportion of the total lecture time was spent on this area of interest. It is also important to acknowledge the various opportunities for external global health exposure afforded to medical students through summer projects, conferences and more. Such opportunities may depend on factors such as geographic region, local global health faculty and institutional global health funding, but nevertheless should be assessed in order to capture the variability of student experiences. Finally, this study did not evaluate institutional global health examination standards. Teaching without assessment will generally be viewed as noncompulsory, particularly by busy medical students, therefore efforts in this discipline should be directed towards robust global health educational examination as well.

\section{Conclusion}

This study serves as the first national assessment of global health education and curricula within UK medical schools. Through a formalised assessment of teaching events produced by medical schools around the country, we were able to capture a national picture of global health education, including the strengths of global health prioritisation in the UK, as well as areas for improvement. Overall, it appears broad-level global health themes are widely discussed; however, the granularities of key, emerging areas of concern are omitted by curricula. In particular, gaps persist relating to international healthcare systems, multilateral global health agencies such as the WHO, global surgery, climate change and more. To facilitate local strengthening of global health educational opportunities, collaborators reported local results to institutional leadership to initiate discussions regarding avenues for satisfaction of the topical gaps in content identified. With models such as GHEMS, we encourage national advocacy bodies and other stakeholders to conduct ongoing status reviews of compulsory global health teachings within their medical schools, with a view to highlight areas for improvement. To equip medical students in the UK with the knowledge to operate, thrive and care for communities in our ever-globalised world, medical schools must vigilantly upgrade current curricula to reflect expert-driven recommendations for global health education. Finally, we perceive and hope that the GHEM $S$ framework will be replicated internationally in order to address the paucity of global health educational literature in medical schools and strengthen the opportunities afforded to students to learn, grow and serve future patient populations. 


\section{Appendix 1}

\section{Complete List of Global Health Themes, Sub-Themes, and Learning Objectives}

The full list of forty-two global health learning objectives is listed below. The forty-two global health learning objectives can be divided into seventeen sub-themes, which fit into five global health thematic elements. Each learning objective, sub-theme, and thematic element was cross-referenced with the GHLOWG learning outcome that it relates to.

Thematic element $\left({ }^{* *}\right)$, Sub- GHLOWG learning outcome
theme $(*)$, and Learning
objective

Global burden of disease**

1. The Health of Populations*

1.1 Access to surgeons with the necessary skills and equipment in different countries

1.2 Mortality and morbidity statistics between countries

1.3 Differences between the leading causes of death and disability in different countries

4 Principles of disease prevention and control in a global setting

1.5 Maternal, reproductive, and child health of various countries

1.6 Nutrition on health

1.7 Mental Health in different countries

2. Migration and Disease*

2.1 Taking a travelling history

2.2 Immunisations for internationa travellers and migrant communities
Global burden of disease

1. Discuss communicable and noncommunicable disease at the global level.

1.4 Describe the major control and prevention initiatives for communicable and noncommunicable diseases that exist at the global level.(Part of the national undergraduate curriculum in surgery)

1.1 Examine and use the key measures of mortality and morbidity to compare the disease burden between regions.

1.2 Describe the leading causes of death and disability at the global level as well as the anticipated trends over time.1.3 Compare and contrast the causes of death and disability between regions and indicate why these variations exist.

1.4 Describe the major control and prevention initiatives for communicable and noncommunicable diseases that exist at the global level.

1.5 Explain the impact of maternal, reproductive and child health on the global burden of disease.

1.6 Explain the impact of poor nutrition on health from a global perspective.

1.7 Explain the importance of mental ill health as a major contributor to the burden of disease worldwide.

2. Discuss the impact of international travel and migration on the diseases seen in the UK.

2.1 Take an appropriate travel history and recognise common causes of illness in a returning traveller.

2.3 Discuss the basis for the use of immunisations for international travellers and migrant communities

Complete List of Global Health Themes, Sub-Themes, and Learning Objectives (Continued)

Thematic element $\left({ }^{* *}\right)$, Sub-

GHLOWG learning outcome theme $(*)$, and Learning

objective

2.3 Diseases commonly seen in certain communities

\section{Pandemics*}

3.1 Causes of pandemics

3.2 Global, national, and local efforts to control pandemics

Socio-economic, cultural, and environmental conditions**

4. Effects of violence and war on health* (also a learning objective)

5. Health inequity* (also a learning objective)

6. Socioeconomic factors affecting health* (also a learning objective)

7. Political factors affecting health* (also a learning objective)

8. Environmental and occupational hazards and ways to mitigate their effects* (also a learning objective)

9. Future impact of climate change on health and healthcare systems* (also a learning objective) in the UK.

2.2 Discuss the aetiology, clinical presentation and management of diseases linked to migration, basing judgement on clinical evidence rather than prejudicial assumption.19. Demonstrate understanding that culture is important and may influence behaviour, while acknowledging the dangers of assuming that those from a particular social group will behave in a certain way

3. Discuss the causes and control of global epidemics.

3.1 Identify the causes of global epidemics.

3.2 Discuss how pandemics should be controlled at the global, national and local levels.

Socio-economic, cultural, and environmental conditions

1.8 Explain the importance of violence and injuries to the global burden of disease.

5. Examine how health can be distributed unequally within and between populations in relation to socially defined measures.

4. Demonstrate awareness of the non-clinical determinants of health, including social, political, economic, environmental and gender disparities.

4. Demonstrate awareness of the non-clinical determinants of health, including social, political, economic, environmental and gender disparities.

4. Demonstrate awareness of the non-clinical determinants of health, including social, political, economic, environmental and gender disparities.6. Describe how the environment and health interact at the global level6.1 Explain how the environment can impact on health, such as through air pollution, flooding and heat waves.

4. Demonstrate awareness of the non-clinical determinants of health, including social, political, economic, environmental and gender disparities.6. Describe how the environment and health interact at the global level6.1 Explain how the environment can impact on health, such as through air pollution, 
Complete List of Global Health Themes, Sub-Themes, and Learning Objectives (Continued)

\section{Thematic element $\left.{ }^{* *}\right)$, Sub- theme $(*)$, and Learning \\ objective \\ GHLOWG learning outcome}

\begin{tabular}{|c|c|}
\hline & $\begin{array}{l}\text { flooding and heat waves.6.2 Explain } \\
\text { the existing and potential future } \\
\text { impact of climate change on health } \\
\text { and discuss ways to mitigate the } \\
\text { effects, both at the individual and } \\
\text { collective levels. }\end{array}$ \\
\hline Organisation of health services** & Health Systems \\
\hline 10. Health systems* & $\begin{array}{l}\text { 8. Recognise that health systems } \\
\text { are structured and function } \\
\text { differently across the globe. }\end{array}$ \\
\hline $\begin{array}{l}10.1 \text { Structure and function of the } \\
\text { NHS }\end{array}$ & $\begin{array}{l}8.2 \text { Describe the structure and } \\
\text { function of the NHS. }\end{array}$ \\
\hline $\begin{array}{l}10.2 \text { Major different national health } \\
\text { system models }\end{array}$ & $\begin{array}{l}8.1 \text { Describe the major different } \\
\text { national health system models. }\end{array}$ \\
\hline $\begin{array}{l}10.3 \text { Primary vs Secondary vs } \\
\text { Tertiary health care }\end{array}$ & $\begin{array}{l}8.4 \text { Discuss the relevance of } \\
\text { primary health care to health } \\
\text { system models }\end{array}$ \\
\hline $\begin{array}{l}10.4 \text { WHO model of the health } \\
\text { system }\end{array}$ & $\begin{array}{l}\text { 7. Discuss the essential } \\
\text { components of a health system, } \\
\text { using the WHO model }\end{array}$ \\
\hline 11. Workforce* & $\begin{array}{l}\text { 9. Recognise that the NHS has an } \\
\text { international workforce and explain } \\
\text { the impact of this within the UK } \\
\text { and overseas. }\end{array}$ \\
\hline 11.1 Diversity in the workforce & $\begin{array}{l}9.1 \text { Discuss the relevance of an } \\
\text { international workforce on national } \\
\text { standards and interprofessional } \\
\text { communication. }\end{array}$ \\
\hline $\begin{array}{l}11.2 \text { Differences between } \\
\text { community and hospital-based } \\
\text { staff }\end{array}$ & $\begin{array}{l}10.3 \text { Examine the causes and scale } \\
\text { of inequalities in health workforce } \\
\text { distribution that exist between } \\
\text { community-based and hospital- } \\
\text { based care }\end{array}$ \\
\hline $\begin{array}{l}11.3 \text { Inequity of distribution of } \\
\text { health and social care } \\
\text { professionals }\end{array}$ & $\begin{array}{l}10.1 \text { Examine the causes and scale } \\
\text { of inequalities in health workforce } \\
\text { distribution that exist between } \\
\text { regions and countries } 10.2 \text { Examine } \\
\text { the causes and scale of inequalities } \\
\text { in health workforce distribution } \\
\text { that exist between urban and rural } \\
\text { areas }\end{array}$ \\
\hline
\end{tabular}

11.4 Different roles within the multidisciplinary team
12. Global governance*
12.1 Role of the $\mathrm{WHO}$

flooding and heat waves.6.2 Explain and discuss ways to mitigate the the individual and collective levels.

8. Recognise that health systems are structured and function

8.2 Describe the structure and 8.1 Describe the major different

8.4 Discuss the relevance of primary health care to health system model

10. Examine the causes and scale of inequalities in health workforce distribution that exist21. Work effectively with colleagues from backgrounds.

Global health governance

12. Discuss the role of the WHO as
12.4 Regulation of research globally

Human rights \& ethics**

13. Law and Ethics*

13.1 Ethics of healthcare delivery different ethnic, religious and social the international representative body of national governments for health.12.1 Describe the functions of the WHO concerning international health policy, disease surveillance, data collection, sharing best practice and setting international norms.

Thematic element $(* *)$, Subobjective

12.2 Private Sector involvement in UK healthcare

12.3 Role of charities and NGOs UK medical practice

14. Human rights* all people
Complete List of Global Health Themes, Sub-Themes, and Learning Objectives (Continued)

GHLOWG learning outcome

8.3 Discuss the involvement of multinational corporations and foreign health systems in delivering health care to UK patients.11. Demonstrate awareness of the complexity of global health governance, including the roles of international organisations, the commercial sector and civil society.

8.3 Discuss the involvement of multinational corporations and foreign health systems in delivering health care to UK patients.11. Demonstrate awareness of the complexity of global health governance, including the roles of international organisations, the commercial sector and civil society.

13. Discuss how health-related research is conducted and governed globally.13.1 Recognise that research trials are subject to rules and guidelines that have been set at the international level.13.2 Explain how the processes of drug research, development and patenting can impact health and access to medicines

Human rights \& ethics

15. Examine how international legal frameworks impact on health care delivery in the UK.20.2 Identify potential ethical concerns relating to the use of family members as translators.

16.2 Discuss and critique how the concept of a right to health impacts on health care delivery in the UK.20.2 Identify potential ethical concerns relating to the use of family members as translators.

13.2 Impact of international law on

15. Examine how international legal frameworks impact on health care delivery in the UK.13.2 Explain how the processes of drug research, development and patenting can impact health and access to medicines 17.2 Recognise that vulnerable groups are protected by specific legal frameworks.

14. Respect the rights and equal value of all people without discrimination and provide compassionate care for all.17.2 Recognise that vulnerable groups are protected by specific legal frameworks.

14.1 Rights and the equal value of

16. Discuss and critique the concept of a right to health.16.1 Discuss the definition of a human 
Complete List of Global Health Themes, Sub-Themes, and Learning Objectives (Continued)

Thematic element $(* *)$, Sub- GHLOWG learning outcome
theme $(*)$, and Learning
objective

objective

right.14.1 Respect patient values and beliefs relating to their health, treatment and end of life care.

14.2 How perceptions may limit opportunities for some people

15. Vulnerable groups* asylum seekers

15.2 Issues of prioritisations

15.3 Legal frameworks vs Medical need

Cultural diversity and health**

16. Communication*

16.1 Tackling prejudice views about certain communities

16.2 Being informed of cultural differences from people from that culture
14. Respect the rights and equal value of all people without discrimination and provide compassionate care for all.14.1 Respect patient values and beliefs relating to their health, treatment and end of life care.

17. Describe the particular health needs of vulnerable groups and migrants.

17.1 Describe the key health needs of refugees, asylum seekers and undocumented migrants in the UK from biomedical, psychological and social perspectives, and how these change over time

18. Discuss the role of doctors as advocates for their patients, including the importance of prioritising health needs over other concerns and adhering to codes of professional conduct.

15. Examine how international legal frameworks impact on health care delivery in the UK.13.2 Explain how the processes of drug research, development and patenting can impact health and access to medicines 17.2 Recognise that vulnerable groups are protected by specific legal frameworks.

Cultural diversity and health

20. Communicate effectively with those from different ethnic, religious and social backgrounds, where necessary using external and examine patients, demonstrating sensitivity to different backgrounds.

2.2 Discuss the aetiology, clinical diseases linked to migration, basing judgement on clinical evidence rather than prejudicial assumption.19. Demonstrate understanding that culture is important and may influence behaviour, while acknowledging the dangers of assuming that those from a particular social group will behave in a certain way

19. Demonstrate understanding that culture is important and may influence behaviour, while acknowledging the dangers of assuming that those from a help.20.3 Conduct a consultation presentation and management of
Complete List of Global Health Themes, Sub-Themes, and Learning Objectives (Continued)

Thematic element $\left.{ }^{* *}\right)$, Sub-

GHLOWG learning outcome theme $(*)$, and Learning

objective

16.3 How to communicate with someone who does not speak English

in a certain way

20.1 Describe how to access external help for translation, including translation services and leaflets in an appropriate language, and recognise how this can impact communication.20.2 Identify potential ethical concerns relating to the use of family members as translators.20.3 Conduct a consultation and examine patients, demonstrating sensitivity to different backgrounds.

17. Health determinants*

19. Demonstrate understanding that culture is important and may influence behaviour, while acknowledging the dangers of assuming that those from a particular social group will behave in a certain way

17.1 Sociology and psychology of the varied responses of groups and societies to disease

19. Demonstrate understanding that culture is important and may influence behaviour, while acknowledging the dangers of assuming that those from a particular social group will behave in a certain way19.2 the doctorpatient relationship

17.2 Health behaviours and outcomes of specific backgrounds

19.1 health-seeking behaviour19.3 the use of alternative medicines and treatments19.4 lifestyle and substance misuse20.4 Access information about the impact of a specific background on health risks.

\section{Appendix 2 \\ Data Collection Template}

Below is a sample of our data collection template. Each row represented a documented teaching session, while each column represented a variable of interest regarding that teaching session. The start of the form collected baseline data pertaining to the key characteristics of the teaching session, while later components were comprised of each learning objective subdivided by theme (e.g. Global Burden of Disease) and sub-theme (e.g. The Health of Populations). Collaborators identified "Yes" or "No" if the teaching sessions fulfilled or did not fulfil the learning objective. 


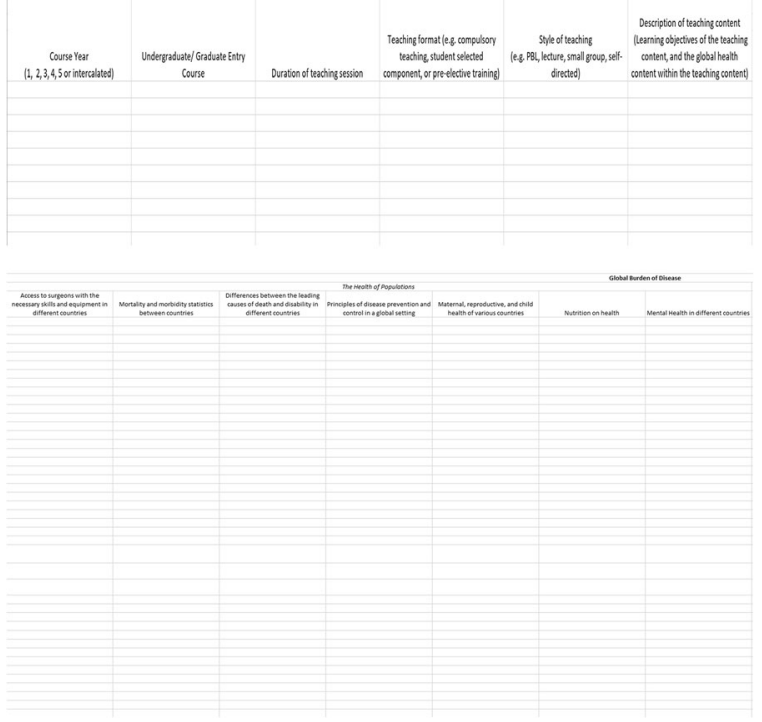

\section{Appendix 3}

Amalgamation of Key Topics Covered in Global Health Education within UK Medical Schools. Topics were derived from the written learning outcomes reported by collaborators for each teaching session. Common themes were synthesised across schools to create an amalgamation of frequently covered topics. This could serve as the beginning of a framework for integrating global health learning objectives into existing compulsory timetabled teaching sessions.

\begin{tabular}{ll}
\hline Global Health Topics & $\begin{array}{l}\text { Topics that can be integrated } \\
\text { into existing timetabled } \\
\text { sessions }\end{array}$ \\
\hline Epidemiology & Epidemiology of communicable \\
diseases \\
- Epidemiology of non- \\
communicable diseases \\
- Mortality statistics at a national/ \\
international level \\
- Morbidity statistics at a national/ \\
international level \\
- Vulnerability to disease \\
- Health of refugees and asylum \\
seekers \\
- Health issues of minority groups \\
- Exploring the factors behind \\
travelling families being less likely \\
to access healthcare \\
opportunities \\
- Defining public health \\
- Preventing Disease \\
- Population level interventions e.g. \\
vaccinations \\
- Health economics and resource \\
allocation \\
- Disease burden \\
- Changing population \\
demographics
\end{tabular}

Appendix 3 (Continued)

\section{Global Health Topics}

Health Systems

Determinants of health

WHO

Organisations involved in healthcare independent from any government
Topics that can be integrated into existing timetabled sessions

- Sustainability as a concept

- Provision of contraception

- Role of the media

- Role of surgery and anaesthesia

- Role of the police

- Role of social services

- Street level bureaucracy

- Sanitisation

- Role of Millennium Development Goals

- Screening programs

- Organisation of services within a healthcare system

- Purpose of the NHS

- Funding of healthcare systems i.e. public vs private

- Service provision

- Current and future challenges facing healthcare

- Clinical governance

- Communication between services within a system

- Role of power in policy process

- Primary vs Secondary vs Tertiary

- Complaints procedures

- Regional differences in service provision

- Genetics

- Nutrition

- Migration

- Social standing

- Prejudice against the disabled

- Prejudice against the aged

- Prejudice against certain cultures

- Prejudice against certain religions

- Prejudice against certain genders

- Prejudice against certain sexualities

- Prejudice against certain ethnicities

- Impact of being in a certain profession

- Impact of certain behaviours on health

- Impact of violence

- Ease of access to services and trained staff e.g. surgeons

- Advantages of wealth

- Living conditions

- Educational attainment

- Adherence to treatment

- Declaration of Alma-Ata

- International prioritisation

- Checklist

- Sustainable development goals

- Health system strategy

- Action on the social determinants of health

- Global Action Plan

- Gates Foundation

- UNICEF

- Doctors of World 
Appendix 3 (Continued)

\section{Global Health Topics}

into existing timetabled

sessions

\begin{tabular}{|c|c|}
\hline & $\begin{array}{l}\text { - Role of charities } \\
\text { - Aid vs trade }\end{array}$ \\
\hline Roles of healthcare professionals & $\begin{array}{l}\text { - Health promotion } \\
\text { - Communicating appropriately } \\
\text { with patients, especially those } \\
\text { who are vulnerable } \\
\text { - Understanding how to balance } \\
\text { patient priorities with clinical } \\
\text { decisions } \\
\text { - Taking a travel and dietary history } \\
\text { - Be involved in research and } \\
\text { quality improvement projects } \\
\text { - Work in a multidisciplinary team } \\
\text { - Act within your competency } \\
\text { - Knowledge of ICER and QALYs } \\
\text { - Educators } \\
\text { - Knowledge of risk and how to } \\
\text { convey it to patients } \\
\text { - Importance of collaborating } \\
\text { within and between professions } \\
\text { - Recognise own prejudices and } \\
\text { assumptions that perpetuate } \\
\text { disadvantages } \\
\text { - Respectful curiosity and empathy } \\
\text { of people from other cultures } \\
\text { - Understand the role of protocols } \\
\text { - Recognise modern slavery and } \\
\text { human trafficking }\end{array}$ \\
\hline Ethics & $\begin{array}{l}\text { - End of life care } \\
\text { - Capacity } \\
\text { - Principle of justice } \\
\text { - Safeguarding } \\
\text { - Euthanasia } \\
\text { - Prejudice } \\
\text { - Abortion } \\
\text { - Genetics } \\
\text { - Data storage } \\
\text { - Autonomy } \\
\text { - Confidentiality } \\
\text { - Research } \\
\text { - Medical Elective } \\
\text { - Human rights } \\
\text { - Organ and tissue retention and } \\
\text { use for transplants }\end{array}$ \\
\hline Laws & $\begin{array}{l}\text { - Mental Capacity Act } \\
\text { - Mental Health Act } \\
\text { - Deprivation of liberties } \\
\text { - Abortion } \\
\text { - End-of-life } \\
\text { - Equality Act } \\
\text { - Taxation } \\
\text { - Disability Discrimination Act } \\
\text { - Child Protection } \\
\text { - Impact on health } \\
\text { - Human fertilisation and embry- } \\
\text { ology act } \\
\text { - Using laws and taxes to modify } \\
\text { behaviour } \\
\text { - EU working time directive } \\
\text { - Declaration of Helsinki } \\
\text { - Female genital mutilation laws }\end{array}$ \\
\hline Patient perspectives & - Impact of stigma \\
\hline
\end{tabular}

Appendix 3 (Continued)

\section{Global Health Topics}

Impact of violence

Politics and health

Environment and health

Communicable diseases

Non-communicable diseases

Child heath
Topics that can be integrated
into existing timetabled sessions

- Impact of stereotyping

- Importance of appreciating the cultural background of a patient

- Role of complementary and alternative medicine

- Need for professional interpreters where language is a barrier

- Importance of doctor-patient relationships

- Impact of illness on patient and their family

- Sources of support for patients

- Importance of their values being considered

- Issues faced by the poor

- Issues faced due to social isolation

- Implications of organ selling

- Health of domestic abuse victims

- How to manage victims of knife crime

- Gender-based violence

- Impact of violence on children

- Impact of female genital mutilation

- Sexual violence and its impacts

- Implications of Brexit on the NHS - Bridging research and policy

- Shaping the way care is provided

- Economics as a driving force for political decisions

- Humanitarian aid

- Impact of climate change on health

- Effects on development

- Impact of pollutants on health

- Natural disasters

- Epidemiology

- Methods of prevention

- Methods of spread

- Methods of controlling spread

- Surveillance

- Outbreaks

- Recognising symptoms

- Antimicrobial resistance

- Long-term impacts

- Recognising symptoms

- Impact of the environment

- Impact of political decisions

- Impact of socio-economic factors

- Changes in trend as the demographic changes

- Aetiology of failure to thrive

- Safeguarding

- Nutrition

- Weaning practices

- Development screening

- Effect of the family on the health of the child

- Effect of the society on the health of the child 
Appendix 3 (Continued)

\section{Global Health Topics}

\begin{tabular}{|c|c|}
\hline & $\begin{array}{l}\text { into existing timetabled } \\
\text { sessions }\end{array}$ \\
\hline & $\begin{array}{l}\text { - Emotional health } \\
\text { - Implications for future health }\end{array}$ \\
\hline Nutrition & $\begin{array}{l}\text { - Risk factors for obesity } \\
\text { - Importance of protected } \\
\text { mealtimes } \\
\text { - Under-nutrition causes and man- } \\
\text { agement } \\
\text { - Challenge of providing adequate } \\
\text { nutrition for the whole global } \\
\text { population } \\
\text { - Water scarcity as a health issue } \\
\text { - Composition of a healthy diet } \\
\text { - Consequences of hunger and } \\
\text { starvation }\end{array}$ \\
\hline Mental health & $\begin{array}{l}\text { - Key issues across the world } \\
\text { - Bias surrounding mental health } \\
\text { - Impact of stigma } \\
\text { - Mental health issues predominant } \\
\text { in each gender } \\
\text { - Service delivery } \\
\text { - Cultural differences in the } \\
\text { symptoms exhibited for mental } \\
\text { illnesses } \\
\text { - Impact of physical disease on } \\
\text { mental health } \\
\text { - Anxiety over medical procedures }\end{array}$ \\
\hline Woman's health & $\begin{array}{l}\text { - Antenatal care } \\
\text { - Pregnancy complications } \\
\text { - Post-partum complications e.g. } \\
\text { fistula } \\
\text { - Barriers to care } \\
\text { - Impact of female genital } \\
\text { mutilation } \\
\text { - Impact of displacement for } \\
\text { maternal health }\end{array}$ \\
\hline
\end{tabular}

\section{Abbreviations}

AMA: American Medical Association; COSECSA: College of Surgeons of East, Central and Southern Africa; GHEMS: Global Health Education in Medical Schools study; HCPs : Healthcare professionals; HSS: Health systems science; LO: Learning Outcome; NHS: National Health Services; UK: United Kingdom; US: United States; WHO: World Health Organisation

\section{Acknowledgements}

Professor Bridget Young for her guidance.

Writing Group: Soham Bandyopadhyay*, Hannah S. Thomas*, Binay Gurung, Isobel Trout, Shavinthi W. Wadanamby, Melika Akhbari, Karisma Sharma, J. Edward Fitzgerald, Ewen M. Harrison, Adrian D. Smith.

*Joint first author.

Data Analysis: Adrian D. Smith, Soham Bandyopadhyay, Isobel Trout, Melika Akhbari, Karisma Sharma.

Steering Committee: Hannah S. Thomas, Soham Bandyopadhyay, Thomas Shortland, Shavinthi W. Wadanamby, Binay Gurung, Melika Akhbari, Isobel Trout, Rashida Patel, Karisma Sharma.

External Advisors: Adrian D. Smith, J.Edward Fitzgerald, Roba Khundkar, Riana Patel, David Clark, Michael Dunn, Oliver Johnson, Ewen M. Harrison, Nusrat Hussain, Dmitri Nepogodiev.

Regional Collaborators: Parivrudh Sharma, Shahnoor M. Amin, Pat Lok, Amir Mohammed, Catherine Dominic, Isobel Trout, Lotta Gustafsson, Abigail Jamieson, Eleanor Deane, Felicity Greenfield, Fiona Jobson, Anmol Arora, Rhys D. Wenlock, Ahmed Bilal, Maarja-Liis Ferry, Chung S. Chai, Hannah S. Thomas, Emma Sharland, James McLaren, Beatrice Prosser, Saud Alfadhel,
Agata Oliwa, Nitish Nachiappan, Muha Hassan, Connor Moore, Pedra Rabiee, Latifa Haque, Mariam Gaddah, Meltem Sarigul, Rashida Patel, Karisma Sharma, Binay Gurung, Alan Penney, Won Y. Yoon, Anuradha Ponnapalli, Katarina Hoernke, Tom Poundall, Isabella Burns, Soham Bandyopadhyay, Annabel Killen, Luisa Hofmaier, Arina Toma, Shavinthi W. Wadanamby, Heather Lawson, James Bevan, Morgan Weiland, Kiana Bowden, Chiara Cotronei, Farhiya Omar, Mariam Ahmed, Jordan Cazier, Emel Yildirim, Belle Liew, Ankit Bhatt, Thomas Shortland, Dilan Parmar.

All the above authors have read and approved the final manuscript.

\section{Authors' contributions}

SB conceived the project. SB, SWW, and TS contributed equally to the design of the project. SB, HST, BG, IT, SWW, MA, KS, JEF, EMH, and ADS drafted the manuscript. All other authors helped draft and extensively reviewed the manuscript. All authors have read and approved the final manuscript. A full authorship list can be found in Acknowledgements.

\section{Funding}

This research has received no specific grant from any funding agency in the public, commercial, or not-for-profit sectors.

\section{Availability of data and materials}

The datasets used and analysed during the current study are available from the corresponding author on reasonable request.

\section{Ethics approval and consent to participate}

Both the King's College London Research Ethics Committee (King's College London) and University of Oxford Medical Sciences Inter-Divisional Research Ethics Committee (University of Oxford) ruled that no formal ethics approval was required in this particular case. All centers provided informed consent for their data to be collected and used.

\section{Consent for publication}

Not applicable.

\section{Competing interests}

JEF is Honorary Clinical Advisor for the LifeBox Foundation (unpaid), Trustee of the Surgical Research Gateway (SURG) Foundation (unpaid), and a consultant for the global healthcare practice at KPMG International (paid). All remaining authors have no competing interests with the aforementioned study or manuscript.

Received: 1 July 2020 Accepted: 16 October 2020

Published online: 28 October 2020

\section{References}

1. Beaglehole R, Bonita R. What is global health? Glob Health Action. 2010;3(1):5142.

2. WHO. Globalization and infectious disease: A review of the linkages. [Internet]. [cited 2020 Feb 17]. Available from: https://www.who.int/tdr/ publications/documents/seb_topic3.pdf.

3. Edith M. Lederer. UN chief warns COVID-19 threatens global peace and security - ABC News [Internet]. [cited 2020 Apr 10]. Available from: https:// abcnews.go.com/US/wireStory/chief-warns-covid-19-threatens-global-peacesecurity-70076937

4. Watson J, Shiner A, Pettigrew LM, Irving G. Global health: time for full integration into GP education. Br J Gen Pract. 2013 May;63(610):271-2.

5. Frenk J, Chen L, Bhutta ZA, Cohen J, Crisp N, Evans T, et al. Health professionals for a new century: Ttransforming education to strengthen health systems in an interdependent world. Lancet. 2010;376(9756):1923-58. https://pubmed.ncbi.nlm.nih.gov/21112623/.

6. Medical Schools Council. The consensus statement on the role of the doctor [Internet]. 2014 [cited 2020 Feb 17]. p. 1-2. Available from: http:// www.medschools.ac.uk/Publications/Pages/Role-of-the-doctor-consensusstatement-2014.aspx.

7. General Medical Council. Duties of a doctor [Internet]. [cited 2020 Feb 17]. Available from: https://www.gmc-uk.org/ethical-guidance/ethical-guidancefor-doctors/good-medical-practice/duties-of-a-doctor.

8. Hilton SR, Slotnick HB. Proto-professionalism: How professionalisation occurs across the continuum of medical education. Medical Education. 2005;39:58-65.

9. Hilgers J, De Roos P. European core curriculum - the students' perspective, Bristol, UK, 10 July 2006. In: Medical Teacher; 2007. p. 270-5. 
10. Stigler FL, Duvivier RJ, Weggemans M, Salzer HJ. Health professionals for the 21st century: A students' view. The Lancet. 2010;376:1877-8.

11. Khan OA, Guerrant R, Sanders J, Carpenter C, Spottswood M, Jones DS, et al. Global health education in U.S. Medical schools. BMC Med Educ. 2013;13(1):3.

12. Johnson O, Lou BS, Willott C, Crocker-Buque T, Jessop V, Birch M, et al Global health learning outcomes for medical students in the UK. The Lancet. 2012;379:2033-5 Lancet Publishing Group.

13. Irving G, Riley B, Rughani A, Pettigrew L, Watson J, Shiner A, et al. Global health in the UK's GP postgraduate curriculum. The Lancet. 2012;380:1646-7 Lancet Publishing Group.

14. Martineau F, Johnson O, Rowson M, Willott C, Yudkin JS. International health graduates-career path experience. The Lancet. 2012;379:2051-2 Lancet Publishing Group.

15. Health I of M (US) C on the UC to G. The U.S. commitment to global health: Recommendations for the public and private sectors. The U.S. Commitment to Global Health: Recommendations for the Public and Private Sectors. National Academies Press; 2009. 1-276 p.

16. Parliament. Lords Hansard text for 20 Dec 2010 [Internet]. [cited 2020 Feb 17]. Available from: https://publications.parliament.uk/pa/ld201011/ldhansrd/ text/101220-0002.htm

17. Commission on Social Determinants of Health. Closing the gap in a generation. 2008.

18. General Medical Council. Tomorrows Doctors - Outcomes and standards for undergraduate medical education. 2009. London: General Medical Council; 2009. p. 1-108.

19. General Medical Council. Generic professional capabilities framework guidance on implementation for colleges and faculties [Internet]. [cited 2020 Feb 17] Available from: https://www.gmc-uk.org/-/media/documents/genericprofessional-capabilities-implementation-guidance-0517_pdf-70432028.pdf/.

20. General Medical Council. Outcomes for graduates 2018 [Internet]. [cited 2020 Feb 17]. Available from: https://www.gmc-uk.org/-/media/documents/ dc11326-outcomes-for-graduates-2018_pdf-75040796.pdf.

21. Brewer TF, Saba N, Clair V. From boutique to basic: A call for standardised medical education in global health. Medical Education. 2009:37:930-3.

22. Velii A. Global health education consortium: 20 years of leadership in global health and global health education. Infect Dis Clin N Am. 2011 Jun;25(2):323-35.

23. Bandyopadhyay S, Shortland T, Wadanamby SW, Thomas HS, Gurung B, Akhbari M, et al. Global Health education in UK medical schools (GHEMS) study protocol. J Glob Heal Reports. 2019;6:3.

24. The Royal College of Surgeons England, (RCSENG). National undergraduate curriculum in surgery 2015. RCSENG - Prof Stand Regul 2015:

25. GlobalSurg Collaborative. Surgical site infection after gastrointestinal surgery in high-income, middle-income, and low-income countries: a prospective, international, multicentre cohort study. Lancet Infect Dis. 2018;18(5):516-25.

26. The Guardian. The NHS produces $5.4 \%$ of the UK's greenhouse gases. How can hospitals cut their emissions? [Internet]. [cited 2020 Feb 17]. Available from: https://www.theguardian.com/society/2019/sep/18/hospitals-planethealth-anaesthetic-gases-electric-ambulances-dialysis-nhs-carbon-footprint.

27. Watts N, Amann M, Ayeb-Karlsson S, Belesova K, Bouley T, Boykoff M, et al. The Lancet Countdown on health and climate change: from 25 years of inaction to a global transformation for public health. The Lancet. 2018;391: 581-630 Lancet Publishing Group.

28. Quintero GA. Medical education and the healthcare system - why does the curriculum need to be reformed? BMC Med. 2014;12(1).

29. Heymann DL, Chen L, Takemi K, Fidler DP, Tappero JW, Thomas MJ, et al. Global health security: The wider lessons from the west African Ebola virus disease epidemic. The Lancet. 2015;385:1884-901 Lancet Publishing Group.

30. Gostin LO. COVID-19 reveals urgent need to strengthen the World Health Organization. JAMA Heal Forum. 2020;1(4):e200559.

31. Carney JK, Schilling LM, Frank SH, Biddinger PD, Bertsch TF, Grace CJ, et al. Planning and incorporating public health preparedness into the medical curriculum. Am J Prev Med. 2011;41(4 SUPPL):3.

32. Gonzalo JD, Dekhtyar M, Starr SR, Borkan J, Brunett P, Fancher T, et al. Health systems science curricula in undergraduate medical education. Acad Med. 2017:92(1):123-31.

33. Gonzalo JD, Haidet P, Blatt B, Wolpaw DR. Exploring challenges in implementing a health systems science curriculum: a qualitative analysis of student perceptions. Med Educ. 2016;50(5):523-31.

34. Meara JG, Leather AJM, Hagander L, Alkire BC, Alonso N, Ameh EA, et al. Global Surgery 2030: Evidence and solutions for achieving health, welfare, and economic development. The lancet. 2015;386:569-624 Lancet Publishing Group.
35. The Royal Colleges of Surgeons in the U.K. and Ireland. The Royal Colleges of Surgeons in the U.K. and Ireland: A common vision for global surgery | The Bulletin [Internet]. [cited 2020 Jun 18]. Available from: https://bulletin. facs.org/2018/05/the-royal-colleges-of-surgeons-in-the-u-k-and-ireland-acommon-vision-for-global-surgery/.

36. Patel R, Khundkar R, Peter N, Turner J, Edgcombe H, Makins A, et al. Improving global surgery education for trainees. Int J Surg Glob Heal. 2019 Oct;2(3):e07.

37. Wellbery C, Sheffield P, Timmireddy K, Sarfaty M, Teherani A, Fallar R. It's time for medical schools to introduce climate change into their curricula. Academic Medicine. 2018;93:1774-7 Lippincott Williams and Wilkins.

38. Finkel ML. A call for action: integrating climate change into the medical school curriculum. Perspectives Med Educ. 2019:8:265-6 Bohn Stafleu van Loghum.

39. Lucey DR, Sholts S, Donaldson H, White J, Mitchell SR. One health education for future physicians in the pan-epidemic 'age of humans'; 2017.

40. Miranda JJ, Yudkin JS, Willott C. International health electives: four years of experience. Travel Med Infect Dis. 2005;3(3):133-41.

41. Blanco-Colino R, Lee S, Kamarajah SK, Vasko P, Kuiper SZ, Farina V, et al. Body mass index and complications following major gastrointestinal surgery: a prospective, international cohort study and meta-analysis. Color Dis. 2018:20(8):0215-25.

\section{Publisher's Note}

Springer Nature remains neutral with regard to jurisdictional claims in published maps and institutional affiliations.

\section{Ready to submit your research? Choose BMC and benefit from:}

- fast, convenient online submission

- thorough peer review by experienced researchers in your field

- rapid publication on acceptance

- support for research data, including large and complex data types

- gold Open Access which fosters wider collaboration and increased citations

- maximum visibility for your research: over $100 \mathrm{M}$ website views per year

At $\mathrm{BMC}$, research is always in progress.

Learn more biomedcentral.com/submission 